\title{
Development of Caring as a Human Science: 50 Years of History of the Korean Society of Nursing Science
}

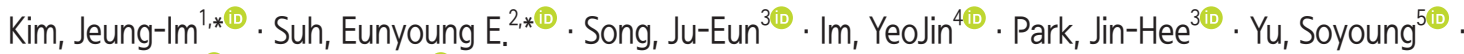 \\ Jang, Sun Joo ${ }^{6 \oplus} \cdot \mathrm{Kim}, \mathrm{Da}-\mathrm{Hee}^{2 \oplus}$ \\ ${ }^{1}$ School of Nursing, Soonchunhyang University, Cheonan \\ ${ }^{2}$ College of Nursing · Research Institute of Nursing Science, Seoul National University, Seoul \\ ${ }^{3}$ College of Nursing · Research Institute of Nursing Science, Ajou University, Suwon \\ ${ }^{4}$ College of Nursing Science $\cdot$ East-West Nursing Research Institute, Kyung Hee University, Seoul \\ ${ }^{5}$ College of Nursing, CHA University, Pocheon \\ ${ }^{6}$ Red-Cross College of Nursing, Chung-Ang University, Seoul, Korea
}

\begin{abstract}
Purpose: This year 2020 marks the 50th anniversary of the founding of the Korean Society of Nursing Science (KSNS). This study was aimed to explore development of caring and describe the 50 years of history of KSNS within the sociocultural context of Korea regarding academic footsteps, meanings, and implications for the future. Methods: This study used a historical research methodology using a literature review and bibliometric analysis. Relevant literature was reviewed and the published abstracts in the Journal of Korean Academy of Nursing (JKAN) were analyzed using VOSviewer. Results: Birth control and family planning in the 1970s was the main research topic. In the 1980s, the development of nursing concepts, theories, and philosophies was the mission of KSNS to extend the disciplinary boundary. In the 1990s, the progress of KSNS to become one of the woman-dominant healthcare professionals was the mission in the given period. Expanding the frontiers of KSNS to the extent of global standards was the undertaking of the nursing scholars in the 2000s. Lastly, in the 2010s, the quality and quantity improvement of KSNS and JKAN is expected to make our future even prosperous. The map visualization of the 50 years of research accumulation showed the comparable opposition of quantitative vs. qualitative research methodologies, equation modeling, and instrument development. Conclusion: These clusters of research demonstrates the efforts to make nursing evidence by Korean nursing scholars for the last five decades. The growth in the slope of KSNS and outcomes of JKAN are to carry on to an unimaginable extent in the future.
\end{abstract}

Key words: Nursing Care; Humans; Societies, Nursing; History of Nursing; Historical Article

\section{INTRODUCTION}

This year 2020 marks the 50th anniversary of the founding of the Korean Society of Nursing Science (KSNS), the leading nursing academic society in South Korea, as well as the
WHO-designated 'The Year of Nurses and Midwives.' In 1970, pioneer nursing scholars launched KSNS with the slogan of 'developing nursing science and disseminating research outcomes' [1]. The performance of KSNS over the past 50 years is remarkable compared to any other academic discipline in modern

*These authors contributed equally as first authors.

Address reprint requests to : Song, Ju-Eun

College of Nursing · Research Institute of Nursing Science, Ajou University, 164 Worldcup-ro, Yeongtong-gu, Suwon 16499, Korea

Tel: +82-31-219-7018 Fax: +82-31-219-7020 E-mail: songje@ajou. ac. kr

Address reprint requests to: $\mathrm{Im}$, Yeolin

College of Nursing Science · East-West Nursing Research Institute, Kyung Hee University, 26 Kyungheedae-ro, Dongdaemun-gu, Seoul 02447, Korea

Tel: +82-2-961-9424Ｆax: +82-2-961-9398Ｅ-mail: imyj@khu. ac. kr

Received: June 20, 2020 Revised: June 22, 2020 Accepted: June 22, 2020 Published online June 30, 2020

This is an Open Access article distributed under the terms of the Creative Commons Attribution NoDerivs License. (http://creativecommons. org/licenses/by-nd/4. 0)

If the original work is properly cited and retained without any modification or reproduction, it can be used and re-distributed in any format and medium. 
Korean history.

The KSNS holds more than 5,000 active members of nursing scientists and clinical nurses. It has eight affiliated academic sub-societies. It produces two international academic journals, the Asian Nursing Research and Journal of the Korean Academy of Nursing, which is listed on the Social Science Citation Index. Additionally, four subject-oriented journals: the Journal of Korean Academy of Community Health Nursing, Korean Journal of Adult Nursing, Korean Journal of Child Health Nursing and Journal of Korean Academy of Fundamentals of Nursing, are listed in the Scopus Database. It hosts biannual national and international nursing conferences, and seasonal workshops and seminars with the topics of current nursing issues.

The importance of the roles of nurses has also been highlighted by the COVID-19 pandemic this year. Through this COVID-19 pandemic, people around the world were allowed to reconsider the importance of nurses' on-the-spot clinical competence and the quality of the healthcare system in each country. The success of infection control on COVID-19 in South Korea attributes to nurses' clinical expertise as well as flexibility and celerity to risk management in the nursing system.

Nurse's official title and roles in medical institutions in history have grown together with the modernization of medicine and technology. Still, it is not an exaggeration to say that the essence of caring began with the origin of human beings. With the long history of social care, nurses in this $4^{\text {th }}$ industrial revolutionary era are unique and special healthcare providers who provide hands-on-care during the entire life cycle from birth to death in an individual's life as well as family and community.

Nursing scientists make invisible caring intentions and practices visible as a human science. They develop concepts and theories emerging from nursing phenomena. Moreover, they designed experimental studies to prove causal relationships between these nursing concepts and methods. This very dynamic and ever-growing discipline - nursing will lead a healthy future for individuals, families, and communities, with its unique and multi-functional competency as scientists, clinical practitioners, and educators.

The beginning and development of contemporary nursing academia in modernized Korea run along a line with the development of KSNS. Herein, the 50 years of history of KSNS was explored and described within the socio-cultural context of Korea regarding academic footsteps, meanings, and implications for the future. This analysis represents how Korean society leaves bigger rooms for nursing as a woman-dominant and human-caring discipline over the last 50 years.

\section{METHODS}

\section{Study design}

This study used a historical research methodology using a literature review and bibliometric analysis. The historical research method is the process of critically examining and analyzing records and the imaginative reconstruction of the past from the data derived by this process [2]. Especially in describing history in nursing, it is necessary to attempt interpreting historical events in association with social, cultural, and political contexts within the realm of the healthcare system and to find the historical value and meaning of nursing [3].

\section{Research data}

The data for this analysis were gathered in three folds. First, for the necessary information regarding Korean societal changes and advances in the healthcare system from the 1970s to the present, a literature review on relevant topics was performed. The articles and book chapters described mutual growth in the healthcare system and nurses' social position in Korea were included. A total of 40 pieces of government documents, articles, and books were collected. Second, the historical publications, conference proceedings, and lists of conference topics by KSNS were obtained and investigated to elicit any possible thematic trends in academic advances throughout KSNS history [4]. Third, the abstracts of published journals on the Journal of Korean Academy of Nursing (JKAN), the primary academic journal of KSNS, for the last 50 years, were retrieved. The number of abstracts reached 3000 , and they became the source of text mining analysis by VOSviewer.

\section{Procedures}

To celebrate the $50^{\text {th }}$ anniversary of KSNS, the editorial board members of JKAN intended to draw a footstep to acknowledge the past achievements and guide the future of nursing academia. 
Through a couple of face-to-face meetings, we lay out a tentative direction of this article and started searching for useful resources. Initially, we planned to analyze the keywords of JKAN published articles qualitatively. However, it was neither appropriate nor possible to analyze as many as around three-thousand keywords using a traditional qualitative method.

Further, the VOSviewer was suggested for the text mining of large volumes of data, such as thousands of abstracts. VOSviewer is computer software that provides constructing and viewing bibliometric mapping in an easy-to-interpret manner using the VOS mapping technique by van Eck and Waltman $[5,6]$. Since its development, it has been successfully used in various disciplines on bibliometric mapping. This software program provides several useful functions related to bibliometric research now $[7,8]$. In this study, we used the VOS mapping function to create and visualize the frequency, co-occurrence, and distances between each word and others out of the ever published English abstracts of JKAN.

\section{Data analysis}

\section{1) Historical analysis}

Collected resources were reviewed and summarized to determine the societal changes and monumental events that advance women's social position and professions. Upon understanding the social context of each decade; these historical occasions were reexamined for any possible relations to the development of contemporary nursing in Korea and the historical references of KSNS. Through weekly online meetings, we came together with the main characteristics of each decade, and their relations with the footprints of KSNS. The themes of international conferences and the main topics of national conferences of KSNS reflected the characteristics of Korean society and nursing as a profession well decade by decade.

\section{2) VOSviewer analysis}

Collected data were analyzed using VOSviewer's function to create a co-occurrence map on terms based on the text data. First, the list of 2,983 articles was modified to the supported file type format for VOSviewer on a 10-year basis. Since the software only provides analyzing functions on text written in English, we excluded 106 articles that only had Korean abstracts or did not have abstracts, and handled 2,877 articles that have English version abstracts (Table 1).

Terms were extracted in the abstract field using the binary counting method, which only counts the existence of a word in one article as one count. 'Threshold' was set to 10 , and terms with $60 \%$ highest ranked 'relevance score' calculated by the software's algorithm was selected as 'items.' 'Threshold 10' and 'selecting 60\% highest score' were the default choices of the program. We adjusted these two values in various ways other than the default choice. Still, we decided to use this default choice as our criteria because default choice made the most explicit demonstration of the map at all periods.

Constructed maps, including all items following the criteria (10 thresholds, 60\% most suitable choice), were presented and each item's occurrences and relevance were demonstrated as a numeric dataset in tables. Further, clusters into which items were grouped were made based on these datasets. After locating maps and these processed datasets, thematic analysis was performed on the clusters that took highly ranked terms in occurrences and relevance into account. Several less-informative or irrelevant terms, such as the research institute and researcher's names, were intentionally excluded.

\section{Ethical considerations}

IRB approval for this study was exempted due to the characteristics of data collected by the authors' affiliated institution.

\section{RESULTS}

The results of this study provided the trends of JKAN research in the sequential development of KSNS with changes in the socio-cultural context of Korea. First, the developmental occasions of KSNS were described within the social context of Korea in the

Table 1. Published Abstracts Out of JKAN for Last 50 Years

\begin{tabular}{crcc}
\hline Year period & $\begin{array}{c}\text { Total article } \\
\text { count }\end{array}$ & $\begin{array}{c}\text { Omitted } \\
\text { articles }\end{array}$ & $\begin{array}{c}\text { Analyzed } \\
\text { articles }\end{array}$ \\
\hline $1970 \sim 1979$ & 179 & 14 & 165 \\
$1980 \sim 1989$ & 201 & 64 & 137 \\
$1990 \sim 1999$ & 589 & 17 & 572 \\
$2000 \sim 2009$ & 1,193 & 8 & 1,185 \\
\hline $2010 \sim 2019$ & 821 & 3 & 818 \\
Total (1970 2019) & 2,983 & 106 & 2,877 \\
\hline
\end{tabular}


given decade. Then, based on the most frequent and highly related items elicited from the abstracts' analysis, the encompassing theme was suggested to represent the characteristics of the decade. The results of the text mining analysis are illustrated in a map for each decade.

\section{The 1970s: Period of establishing Nursing Academic Society and main domestic journal}

\section{1) Social changes and nursing development in 1970s}

In the 1970s, the ratio of labor force participation rate of women was $38.5 \%$, meaning that only four tenth women had a job, and nurses were one of the primary tasks for women working in a professional field [9]. The revision of the Mother and Child Health Law in 1973 called out the necessity of improving women's higher education in the 70s. In nursing, the official nurse licensure issued by the Minister of Health and Social Affairs began to provide nurse license to graduates of nursing college and post-graduate level schools in 1973 with the revision of Medical Law. The first doctorate program in nursing was opened at Yonsei University in 1978, followed by Ewha Womans University in 1979, which indicated the advancement of nursing academia [10].

Based on the impending necessity for a nursing academic society representing the body of nursing scholars in Korea, the Korean Academy of Nursing (KAN), the former body of KSNS was launched in April 1970. The goals of KAN were to improve the research competences of nursing scholars and to communicate with international nursing academic societies as a representative of the Korean nursing academic society. As the first academic journal of KAN, the Journal of Nurses Academic Society (JNAS) was published in December 1970, which is the former name of JKAN. The JNAS issued two volumes each year until 1984, and then the issues per year increased to 3 times. The themes of conferences mainly focused on identifying nursing as a science and profession, learning research methodology, and importing Western nursing education and research systems (Appendix 1). In the 1970s, the KAN was born under societal and internal needs for an academic nursing society, and the KAN began its educational activities through JNAS.

\section{2) Attributes of published studies in $1970 \mathrm{~s}$}

In the 1970s, a total of 179 articles were published. The top30 frequently used words in terms of their occurrence and relevance are listed (Appendix 2). In particular, the top-ranked words were grouped as clusters based on each word's relation to the others. Through a deliberate semantic analysis of top-ranked words, word clusters, and substantive meanings of the words in nursing research, four clusters were named in the 1970s. The $1^{\text {st }}$ cluster was about 'women's reproductive health,' including terms such as pregnancy, rate, infant, baby, and woman. The $2^{\text {nd }}$ cluster was about developing 'nursing science and knowledge,' including words such as knowledge, research, development, nursing, and science. The $3^{\text {rd }}$ cluster was on 'nursing education,' including the terms, for instance, student, educational level, understanding, and clinical experience. The $4^{\text {th }}$ cluster was again related to 'family planning,' containing child, female, family planning, and home.

The $1^{\text {st }}$ and $4^{\text {th }}$ clusters of 'women's reproductive health' and 'family planning' are considered to reflect the fact that the national health policy underlining family planning and birth control in the 1970s influenced nursing research. The $2^{\text {nd }}$ and $3^{\text {rd }}$ clusters of developing 'nursing knowledge as a science' and 'nursing education,' were the results of the demands for professional nursing and education with higher quality in those days. The word map of the 1970s illustrated those four features, but the clusters were somewhat scattered than prominent (Figure 1).

In the 1970s, as the $1^{\text {st }}$ nursing academic society in Korea, KAN was established, and the foundation for the production of nursing research and publications was grounded. Pioneering nursing leaders who founded KAN were the same group of people who originated at the graduate level of nursing education in Korea. JNAS was initiated as the face of KAN, presenting the fact that caring could become scientific. JNAS rigorously attempted to develop nursing science and indigenous knowledge in Korea by publishing as diverse and scientific as possible to become a platform for nursing research in the 1970s. In summary, the formation and activities of KAN and JNAS in the 1970s were schematized with the theme of the 'Period of Establishing Nursing Academic Society and Main Domestic Journal.' 


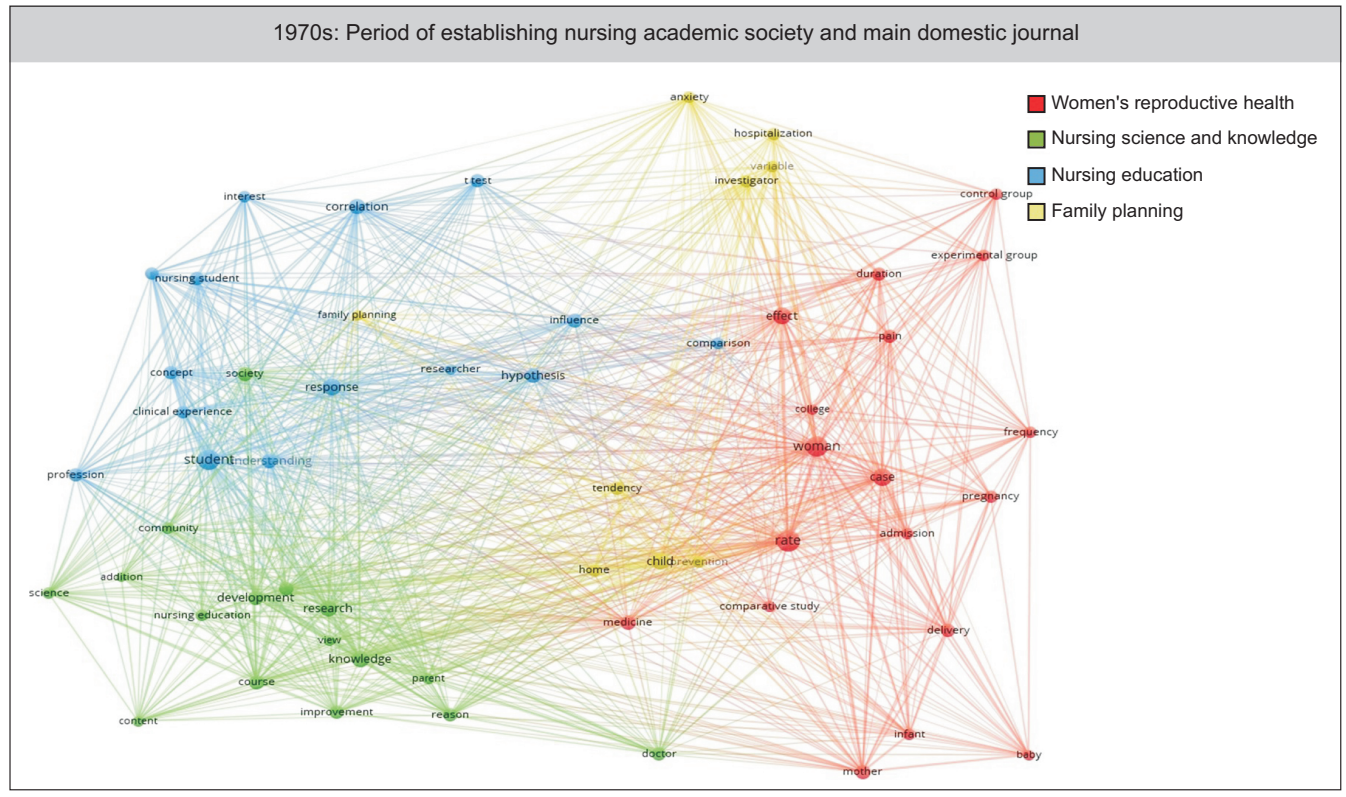

Figure 1. 1970s' map visualization by their occurrence and relevance.

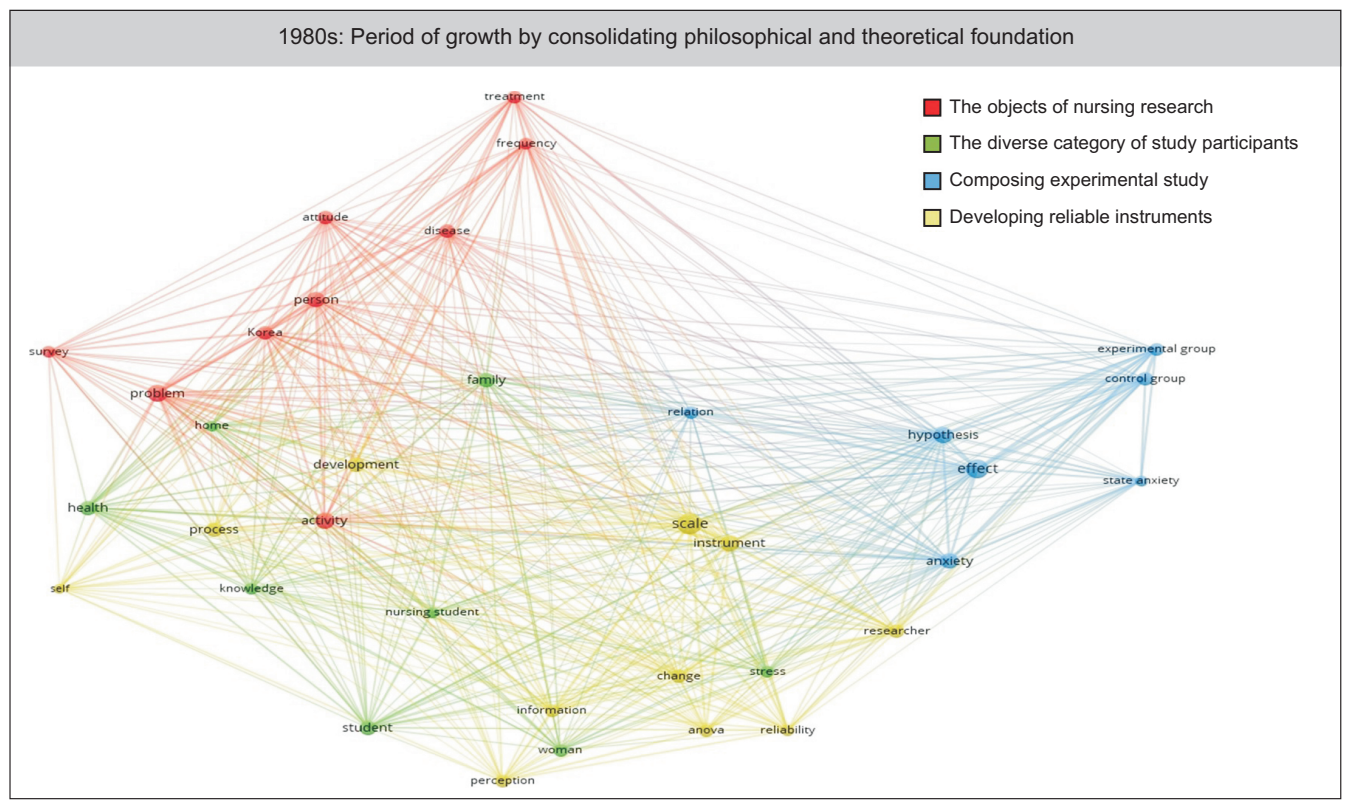

Figure 2. 1980s' map visualization by their occurrence and relevance.

\section{The 1980s: Period of growth by Consolidating Philosophical and Theoretical Foundation}

\section{1) Social changes and nursing development in 1980s}

In the 1980s, women's employment rate continued to increase, reaching $41.6 \%$, and the employment ratio of female college graduates to males increased to $16.4 \%$. Women aged 25 34 years, however, have been shown to withdraw from the labor market for reasons such as marriage, childbirth, and parenting [11]. In 1987, the Sexual Equality Employment Act was enacted, which aimed to realize gender equality by guaranteeing equal opportunities for men and women in employment, while protecting motherhood, supporting work, and family life.

In nursing education, three more universities established doc- 
toral programs, including Seoul National University in 1984, Kyungpook National University in 1985, and the Catholic University in Korea in 1988 [10]. As an activity of the Korean Academy of Nursing, regular general meetings and academic conferences were held every year in the 1980s, and the spring and fall conferences were held twice a year from 1985. Additionally, various types of educational activities, such as seasonal workshops and seminars, were actively hosted by not only KAN but also by subdivision nursing societies. The International Nursing Conference (INC) was held in 1984 and second in 1989.

Since the theme, "the 1980s is the year of nursing theory development," was entitled at the KAN conference in 1980, nursing concepts, theories, and philosophies undergird in nursing were actively discussed in many nursing conferences. Nursing theorists such as Newman in 1987, Rogers in 1988, and Meleis in 1989, to name a few, were introduced to Korean nursing scholars, and their applications were discussed. The yearly issues of JNAS increased from 2 to 3 in 1985, and JNAS was listed on the nursing index in 1988 (Appendix 1) [4].

\section{2) Attributes of published studies in 1980s}

In the 1980s, a total of 201 papers were published in JNAS. The $1^{\text {st }}$ cluster that came out of text mining was 'the objects of nursing research,' such as a person, activity, attitude, disease, treatment, and problem, which mostly fell into the four nursing meta-paradigm (i.e., human, health, environment, and nursing). During this period, 'the diverse category of study participants,' including woman, nursing student, stress, religion, age, and family was named as the $2^{\text {nd }}$ cluster. A group of words like hypothesis, experimental and control group, effect, and sample, etc., was clustered together as $3^{\text {rd }}$ one, entitled, 'composing an experimental study'. As the $4^{\text {th }}$ cluster, the words, for example, scale, instrument, development, reliability, and process, were grouped as 'developing reliable instruments' (Appendix 2).

As school of nursing with a Ph.D. program increased in 1980s, nursing scholars from those schools tried to establish a philosophical foundation for nursing discipline and to identify the discriminant knowledge of nursing. The $1^{\text {st }}$ and $2^{\text {nd }}$ clusters reflected those efforts to define the boundaries of nursing knowledge; in results, nursing researchers discoursed on four nursing meta-paradigms (i.e., human, health, environment, and nursing).
Studies using experimental or survey design and reliable instruments were dominant in the 1980s, which emerged as $3^{\text {rd }}$ and $4^{\text {th }}$ clusters as well as depicted in text maps. The words were still scattered but eminent enough to represent the four clusters (Figure 2). In summary, the phase of the fast-developing period of the 1980s, by developing the nursing discipline and its theories, was named as 'Period of Growth by Consolidating Philosophical and Theoretical Foundation.'

\section{The 1990s: Period of taking a leap toward scientific and professional discipline}

\section{1) Social changes and nursing development in 1990s}

The participation rate of women in economic activities increased to $47.0 \%$ in 1998 . The employment rate in their 20s and 40s increased; however, their career was cut off by childbirth and parenting in their 30s, showing a distinctive M-shaped pattern [10]. As women's employment issues related to gender characteristics emerged, various efforts to prevent gender discrimination in employment and to ensure gender equality, including the Basic Act on Women's Development in 1995, the goal for female employment rate in 1996, and the Gender Discrimination Act in 1999.

Regarding nursing education, the number of 4-year colleges of nursing increased from 19 in 1990 to 49 in 1999, demonstrating quality education across the nation. However, the number of three-year colleges (57.5\%) surpassed those of 4-year colleges (42.5\%) in 1999. To unify the nursing educational system, the so-called 'RN to BSN' program, which provides RNs with bachelor degrees after two years of course work, was established in 1996. For quality control of higher education, the Korean Council for University Education began the evaluation and accreditation of college education in 1994 [12].

Regarding the academic activities of KAN, various educational activities, including regular general meetings, academic presentations, and annual conferences, were established in the 1990s. In the results of many efforts to hold international nursing conferences more regularly, six international nursing conferences were held in the 1990s. The conference themes in the 1990s were related to nursing professionalism to become scientific in structure and methods. To address a few, 'scientific approaches to achieve nursing professionalism' in 1992, 'nursing profession- 
alism and nursing education' in 1993, and 'nursing education for nursing professionalism' in 1995 were exemplars.

Another trend shown in the 1990s was the emphasis on research methodology to be more rigorous investigating invisible nursing phenomena. Along the line, attention to qualitative methodology increased. In the results, a couple of conferences took the types of qualitative methods as their main topics, such grounded theory methodology and ethnography in 1991 (Appendix 1). The number of articles had published in JNAS reached almost 600 by the end of 1999. The name of the journal was changed to the Journal of Academy of Nursing in 1995. In 1997, the name changed again to the Journal of the Korean Academy of Nursing (JKAN) as it is currently. From 1997 to now, only one volume in 1998 had a different journal name (i.e., the Korean Academy of Nursing Journal) from JKAN. In the 1990s, it seemed that there were a lot of considerations about journal names. JKAN was listed on the candidate journals of the Korea Citation Index in 1999. Furthermore, the English edition of JKAN was issued for the first time in 1999. Since then, it has been released once a year.

\section{2) Attributes of published studies in 1990s}

In 1990, a total of 589 articles was published, demonstrating an excessive productivity growth of almost three times that of the previous decade. The text-mining results showed four clusters about the research methods and their objects. The $1^{\text {st }}$ distinct cluster was the introduction of "qualitative research methodology,' which included words such as experience, meaning, category, theme, and perspective. The $2^{\text {nd }}$ cluster was characterized by the 'specified quantitative research,' composing the phrase such as t-test, ANOVA, Sheffe test, multiple regression, and significant difference. 'Nursing education and practice' were the $3^{\text {rd }}$ clusters, which became the entities of nursing research, including words such as nursing practice, clinical practice, curriculum, and system. Finally, the 'use of bio-data' was identified as the $4^{\text {th }}$ cluster, including blood pressure, body weight, significant change, effect, test, and exercise (Appendix 2).

The gradual growth of survey studies was followed by more sophisticated and inventive research designs using correlations or t-test, Sheffe test as a post-hoc test, utilizing bio-data, and investigating nursing education and practice. As a counterpart of quantitative research methodology, the introduction of qualitative ones was welcomed by nursing scholars in those days, given the fact that many aspects of nursing phenomena heavily relied on invisible relations and existence.

In those days, nursing scholars seemed to struggle to make nursing as a professional discipline by expanding the realm of research methodology and by exploring more refined research methods. These efforts are implied in the 4 clusters mentioned above and the text map. It was evident that the published studies in JKAN were grouped into either qualitative (colored in red) or quantitative (colored in green) realms (Figure 3). In summary, the 1990s, the period characterized by dramatic growth and diverged research methods, was named as 'Period of Taking a Leap toward Scientific and Professional Discipline.'

\section{2000's: Period of becoming a global nursing society and an influential journal}

\section{1) Social changes and nursing development in $2000 \mathrm{~s}$}

The Ministry of Gender Equality was established in 2001, the Bisexual Equal Employment Objective System in 2003, the Act on the Promotion of Family-Friendly Social Environment, and the Career Interruption Women Act in June 2008, which were expected to promote women's economic activities [13]. However, it has been pointed out that the low percentage of women in high-ranking positions, the gender wage gap, and women's career disconnection problems caused by pregnancy, childbirth, and childcare remain social issues [13].

Concerning nursing education, 32 master's programs, and 15 doctoral programs were established as of 2001 [14]. In the field of healthcare, the medical institution assessment system was intensified to accreditation systems, forcing medical institutions to improve patient safety and the level of healthcare quality [15]. For nursing quality education, the Korean Accreditation Board of Nursing Education (KABONE) was established in 2003 and authorized by the Ministry of Health and Welfare in 2004 [16]. The $1^{\text {st }}$ accreditation for an undergraduate program and $1^{\text {st }}$ approval of a master's program for advanced practice nursing occurred in 2005 [16].

The name 'Korean Academy of Nursing' of the organization was changed to the 'Korean Society of Nursing Science' in 2005 and joined as a member of the "World Academy of Nursing Sci- 
ence' in 2009. In 2001, JKAN was listed on the Korea Citation Index and so much as Medline and Scopus in 2004. Under the continued efforts to develop JKAN as a competitive nursing journal, the JKAN has finally listed on the Social Science Citation Index (SSCI) journal lists and Science Citation Index Expanded (SCIE) journal lists in 2008. In the $30^{\text {th }}$ anniversary of the KSNS and the new millennium in 2000, various conferences and academic symposiums were held with themes, including 'nursing leadership,' 'nursing and informatics society,' 'collaborative nursing research,' and 'inter-professional education' to name a few (Appendix 1).

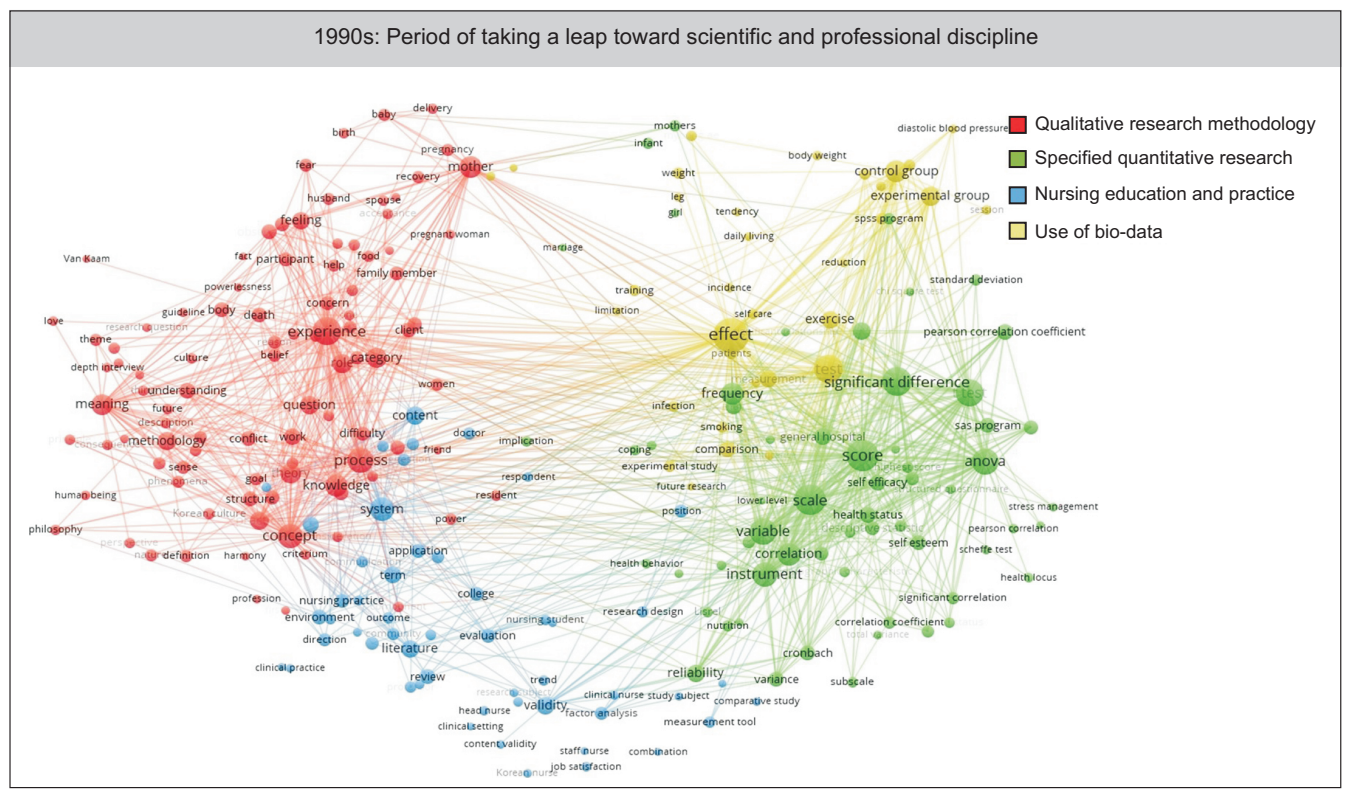

Figure 3. 1990s' map visualization by their occurrence and relevance.

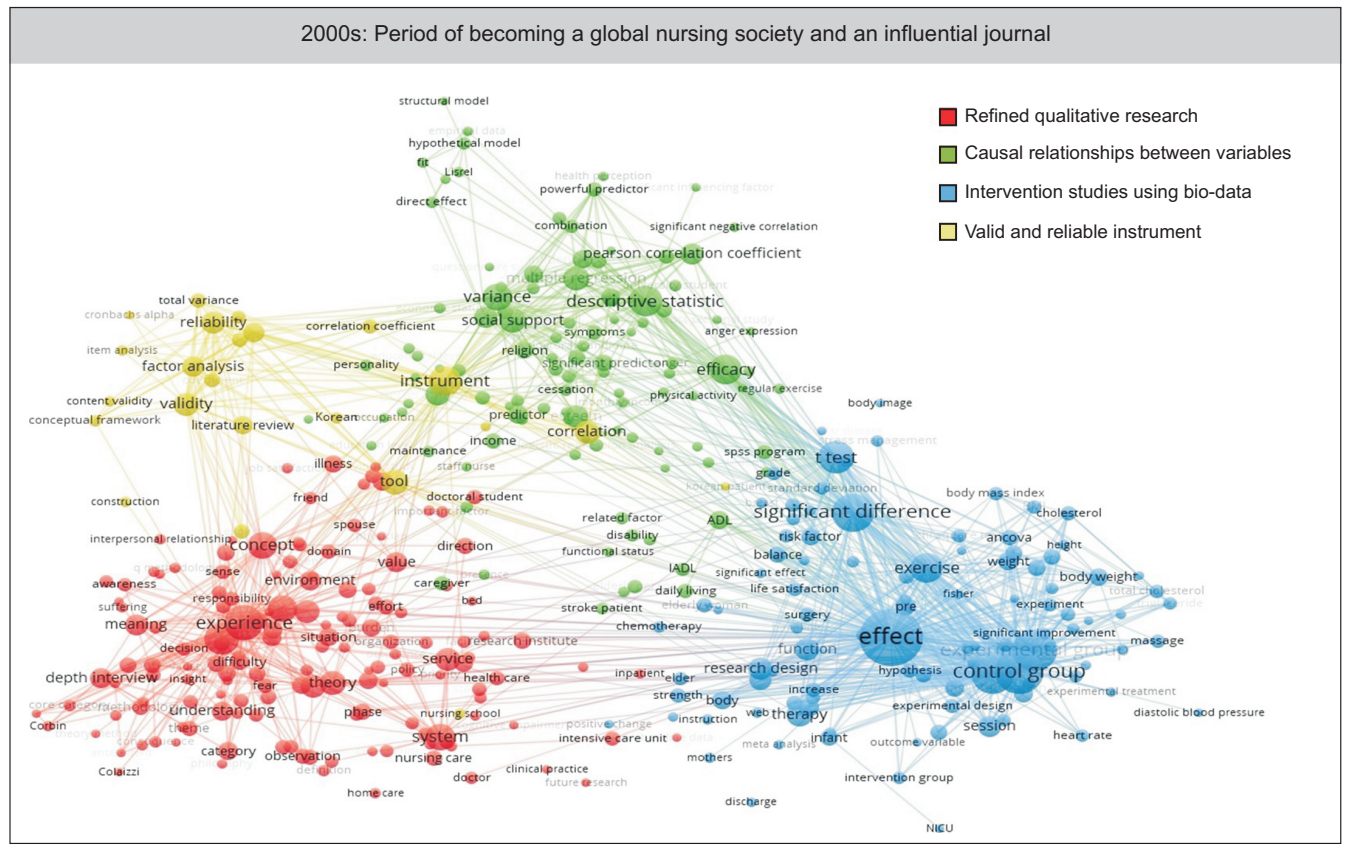

Figure 4. 2000s' map visualization by their occurrence and relevance. 


\section{2) Attributes of published studies in $2000 \mathrm{~s}$}

A total of 1,193 articles was published in the 2000s, almost doubled compared to the previous decade. In particular, six times more than those in the 1970s. More than thousands of abstracts illustrated three relatively prominent clusters and one less noticeable cluster through a text mining analysis as well as in a text map. The $1^{\text {st }}$ cluster was about 'refined qualitative research,' showing that the methods got more advanced and detailed, including the words such as concept, Strauss, Corbin, Q statement, Colaizzi, core category, and theory (Figure 4).

The $2^{\text {nd }}$ cluster was on research investigating 'causal relationships between variables,' including words such as multiple regression, hypothetical model, structural model, path, and efficacy. Conducting 'intervention studies using bio-data,' the $3^{\text {rd }}$ cluster, emerged including words such as height, body weight, BMI, total cholesterol, diastolic blood pressure, and heart rate. The last $4^{\text {th }}$ cluster, developing a 'valid and reliable instrument,' was represented by words such as validity, reliability, preliminary item, item analysis, and Cronbach alpha (Appendix 2). The world map of this period depicted four clusters in colors that showed the accumulated body of nursing knowledge in the 2000s (Figure 4).

The nursing scholars in the 2000s flourished nursing academia by publishing the most substantial volume of articles in JKAN ever and investigating deeper and broader dimensions of target phenomena in terms of the research methodology, target population, and analysis technique. In the 2000s, the KSNS became a member of the World Academy of Nursing. In the same period, JKAN was listed on SSCI/SCIE together. Given these exceptional outcomes in Korean nursing history, the 2000s are named as 'Period of Becoming a Global Nursing Society and an Influential Journal'.

\section{The 2010s: Period of Expansion and sophistication on research method and analysis}

1) Social changes and nursing development in $2010 \mathrm{~s}$

The ratio of labor force participation in the field of healthcare was $21.4 \%$ among the rate of women labor force $49.4 \%$ in 2010 , which meant that almost half of working women belonged to the field of healthcare. The ratio of women leaders in high-position jobs has continuously increased from $17.5 \%$ in 2005 to $22.8 \%$ in 2014. With the societal issues of aging and chronic disease, policies such as the efficient distribution of healthcare resources, expansion of public healthcare facilities, quality healthcare, specialization of medical services, and increasing hospice services were suggested [17,18].

The implementation of the $2^{\text {nd }}$ round accreditation on nursing education programs by the KABONE was performed. There was a numeric expansion of school of nursing in a short period in lieu of the shortage of nurses in healthcare. A total of 22 doctoral programs and 33 master's programs took the role of providing education to graduate nursing students in 2010 (Appendix 1).

The themes of nursing education, humanity oriented nursing

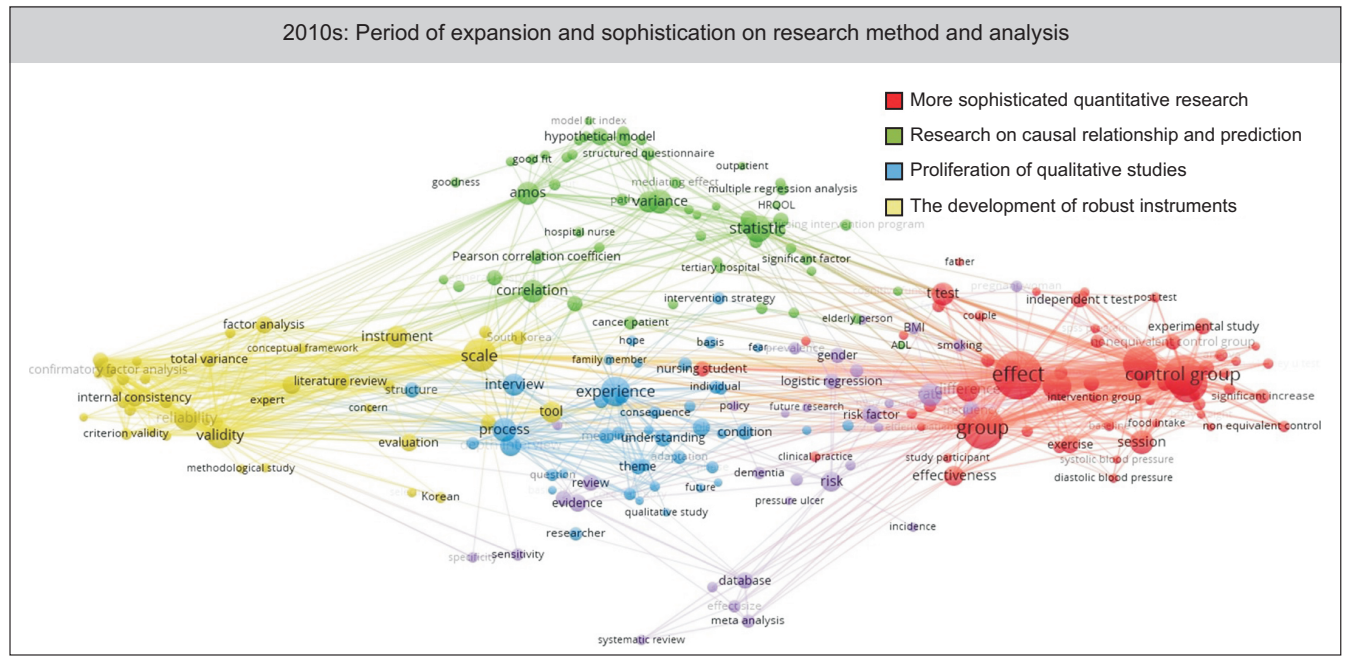

Figure 5. 2010s' map visualization by their occurrence and relevance. 
environment, utilization of translational research, and discipline of convergence were discussed in the KSNS conferences. Moreover, academic discussions on vulnerable populations, including the elderly, children with illness, women with multicultural backgrounds, and patient safety were held. Reflecting on the features of the $4^{\text {th }}$ industrial revolution in the healthcare system, the utilization of big data, healthcare systems and policies, and inter-professional practices were also deliberated in conferences. JKAN became an open-access journal in 2013, publishing both Korean and English articles and providing the full-text JATS XML in 2014, and utilizing the online submission and management system in 2017 (Appendix 1).

\section{2) Attributes of published studies in $2010 \mathrm{~s}$}

In the 2010s, a total of 821 articles was published in JKAN, with approximately a $30 \%$ decrease in the number compared to the previous decade. The reason for the reduction was estimated because of the foundation of the Asian Nursing Research (ANR), the English version journal of KSNS, in 2007, and its SSCI/ $\mathrm{SCI}(\mathrm{E})$ listing in 2010. It is assumed that the research products of Korean nursing scholars were split in both JKAN and ANR in the 2010s. Nonetheless, with better research quality in terms of methodology and analysis technique, the articles in the 2010s were grouped into four similar but more compound clusters compared to the 2000s.

'More sophisticated quantitative research' was the $1^{\text {st }}$ cluster, including words such as pretest-posttest design, significant difference, and nonequivalent control group. This result demonstrated that the methodology was broadened and solidified. Besides, 'research on the causal relationship and prediction' emerged as the $2^{\text {nd }}$ cluster, showing the advances in research types. Words such as AMOS, hypothetical modeling, and model fit belonged to the given cluster. 'Proliferation of qualitative studies,' the $3^{\text {rd }}$ cluster, composed a group of words, such as in-depth interviews, processes, contexts, meanings, and core categories. It validated the increased number of qualitative studies and the expansion in the depth of the methodology. The last cluster was about 'the development of robust instruments,' including words such as total scale, factor loading, confirmatory factor analysis, and criterion. Specified nursing scales appropriate to Koreans were developed in the studies of the given cluster (Appendix 2).
In the 2010s, the studies became more sophisticated in methodology and broadened in target phenomena. The word map in the decade illustrated four prominent colors representing each cluster, which proved the fact that each study contributed to making nursing evidence (Figure 5). Considering the feature of each cluster with diversity and advancement, the 2010s is named as 'Period of Expansion and Sophistication on Research Method and Analysis.'

\section{DISCUSSION: A SUMMARY OF THE 50 YEARS}

Since its establishment as the $1^{\text {st }}$ nursing academic society in Korea in 1970, KSNS has been grown histrionically in its quality outcomes. From its origin by a few nursing scholars, it is now grown to be the most significant academic nursing society with more than five thousand members. INC is held every other year, and seasonal workshops and national conferences are hosted regularly. In particular, INC has become a renowned international gathering of nursing scholars from many Asian countries.

To summarize each decade, birth control and family planning, as one of the characteristics of developing countries, as well as social issues in the 1970s, was the main research topic. In the 1980s, the development of nursing concepts, theories, and philosophies was the mission of KSNS to extend the disciplinary boundary. In the 1990s, the progress of KSNS to become one of the woman-dominant healthcare professionals was the mission in the given period. Expanding the frontiers of KSNS to the extent of global standards was the undertaking of the nursing scholars in the 2000s. Lastly, in the 2010s, the quality and quantity improvement of KSNS and JKAN is expected to make our future even prosperous.

The accumulation of 50 years of research portrayed a distinctive picture of the footprints of our ancestors (Figure 6). The most significant cluster came out of text mining analysis was about 'words related to quantitative research,' which was comparative to 'the words of qualitative research' in the $2^{\text {nd }}$ cluster. The 'effect' was the most frequently used word in the $1^{\text {st }}$ cluster; meanwhile, 'experience' was the most used word in the $2^{\text {nd }}$ cluster. The $3^{\text {rd }}$ cluster was about 'equation modeling,' which was represented by 'model' as the most used word. The validity was the word designating the $4^{\text {th }}$ cluster, 'development of a quality 


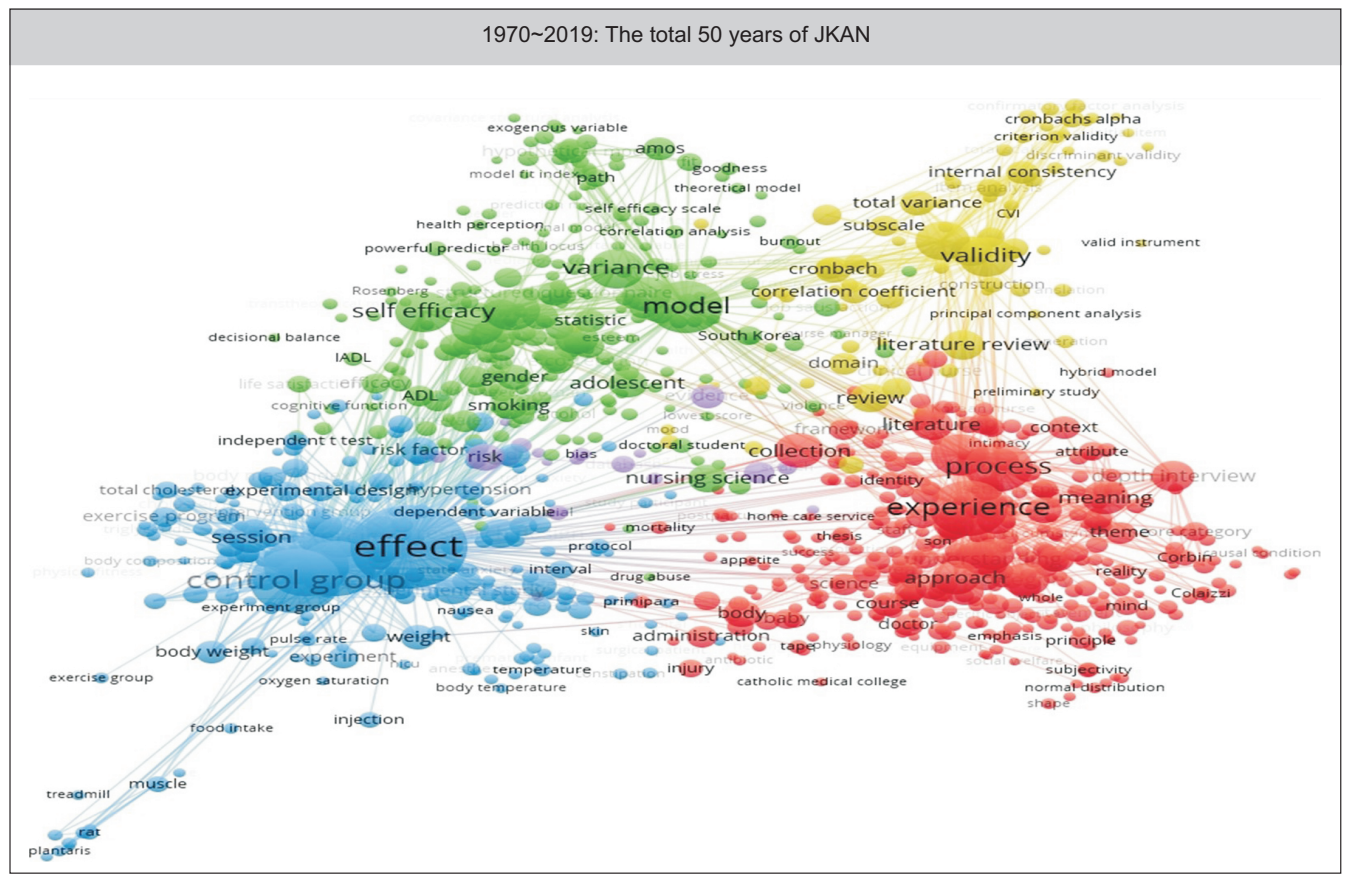

Figure 6. The map visualization for 50 years by their occurrence and relevance.

instrument.

The quadrilateral shape of the map provided insights into three ways. The first insight is that the 50 years of JKAN outcomes could be segregated in four different research areas. Second, the types of methodology used in JKAN research are quantitative, as many as three-fourths of the total outcomes. The last insight is about the incommensurability between logical positivism and constructivism. The distance between $1^{\text {st }}, 3^{\text {rd }}, 4^{\text {th }}$ clusters to each other, which are named as 'quantitative research,' 'equation modeling,' and 'instrument development' respectively, is closer than the distance from $1^{\text {st }}, 3^{\text {rd }}$, and $4^{\text {th }}$ to $2^{\text {nd }}$ cluster, 'qualitative research.' In summary, through this quadrilateral shape of research accumulation, the advances in nursing science and divergence of research realms were explained.

\section{CONCLUSION}

In this article, the history of KSNS and JKAN were reviewed within the socio-cultural context of Korea, and the published articles were analyzed using text mining techniques. The map of the 50 years of research accumulation showed the comparable opposition of quantitative vs. qualitative research methodologies, equation modeling, and instrument development. These clusters of research demonstrates the efforts to make caring as a human science by Korean nursing scholars for the last five decades. The growth in the slope of KSNS and outcomes of JKAN are to carry on to an unimaginable extent in the future.

\section{CONFLICTS OF INTEREST}

The authors declared no conflict of interest.

\section{ACKNOWLEDGEMENTS}

All authors would like to appreciate to Hee Joo Kim of the editorial office of JKAN for her special supports on this work.

\section{AUTHOR CONTRIBUTIONS}

Conceptualization or/and Methodology: All authors.

Data curation or/and Analysis: Suh EE \& Song JE \& Im YJ \& Kim DH.

Funding acquisition: Kim JI.

Investigation: All authors.

Project administration or/and Supervision: Kim JI \& Suh EE \& Song JE \& Im YJ. 
Resources or/and Software: Song JE \& Kim DH.

Validation: All authors.

Visualization: Kim JI \& Suh EE \& Song JE \& Im YJ \& Kim DH.

Writing original draft or/and Review \& editing: All authors.

\section{REFERENCES}

1. Korean Society of Nursing Science (KSNS). Introduction [Internet]. Seoul: Korean Society of Nursing Science (KSNS); c2011 [cited 2020 Jun 9]. Available from: http://www.kan. or.kr/content/about/intro.php.

2. Glass LK. Historical research. In: Wood MJ, Brink PJ, editors. Advanced Design in Nursing Research. 2nd ed. Thousand Oaks (CA): SAGE Publications Inc; 1998. p. 356-374.

3. Hah YS. Research: Perception of social support in pregnancy, and process of labor and delivery among primiparous women. Korean Journal of Nursing Query. 2000;9(2):76-78.

4. Korean Academy of Nursing. 30-year history of the Korean Academy of Nursing. Seoul: Korean Academy of Nursing; 2002. p.1-199.

5. van Eck NJ, Waltman L. VOS: A new method for visualizing similarities between objects. In: Decker R, Lenz HJ, editors. Advances in Data Analysis. Heidelberg: Springer, Berlin, Heidelberg; 2007. p. 299-306.

6. van Eck NJ, Waltman L. Software survey: VOSviewer, a computer program for bibliometric mapping. Scientometrics. 2010;84(2):523-538. https://doi.org/10.1007/s11192-009-0146-3

7. Leydesdorff L, Carley S, Rafols I. Global maps of science based on the new Web-of-Science categories. Scientometrics. 2013;94(2):589-593. https://doi.org/10.1007/s11192-012-0784-8

8. Saheb T, Saheb M. Analyzing and visualizing knowledge structures of health informatics from 1974 to 2018: A bibliometric and social network analysis. Healthcare Informatics Research. 2019;25(2):61-72. https://doi.org/10.4258/hir.2019.25.2.61
9. Hong KJ, Tak YR, Kang HS, Kim KS, Park HR, Kwag WH, et al. The job stress, job satisfaction, and health of women who work in the professional job: Nurses and teachers. Journal of Korean Academy of Nursing. 2002;32(4) :570-579. https://doi.org/10.4040/jkan.2002.32.4.570

10. Oh K, Park YS, Lee JH, Oh KO, Ahn YH, Lim J. A historical trends of doctoral nursing education in Korea. The Journal of Korean Academic Society of Nursing Education. 2014;20(1):93-107. https://doi.org/10.5977/jkasne.2014.20.1.93

11. Yoo O. Economic development and economic position of women's labor. The Journal of Asian Women. 2004;43(1):237-267.

12. Hwang IS. The achievement of university evaluation to improve the quality of universities- focused on the university evaluation of the Korean council for university education. Higher Education. 2008; (152): 72-76.

13. Kim S. Women's economic participation in Korea(2000 2013). The Journal of Political Science \& Communication. 2015;18(2):223-248. https://doi.org/10.15617/psc.2015.06.18.2.223

14. Park ES, Yang SO, Kim SS, Yang S, Park YJ, Ha NS, et al. Analysis of the nursing curricula in graduate programs in Korea. Journal of Korean Academy of Nursing. 2002;32(1):100113. https://doi.org/10.4040/jkan.2002.32.1.100

15. Korea Institute for Healthcare Accreditation (KOIHA). History [Internet]. Seoul: KOIHA; c2012 [cited 2020 Jun 10]. Available from: http://www.koiha.kr/member/en/contents/ensub01/ ensub01_04.do.

16. Korean Accreditation Board of Nursing Education (KABONE). History [Internet]. Seoul: Korean Accreditation Board of Nursing Education (KABONE); [cited 2020 Jun 10]. Available from: http://www.kabone.or.kr/eng/kabon01/index03.php.

17. Doh SR. Changes of medical utilizations and issues on health care policies. Health and Welfare Policy Forum. $2005 ;(102): 65-76$.

18. Lee SY. Health policy 2010: changes and outlook. Health and Welfare Policy Forum. 2010; (159) :15-20. 


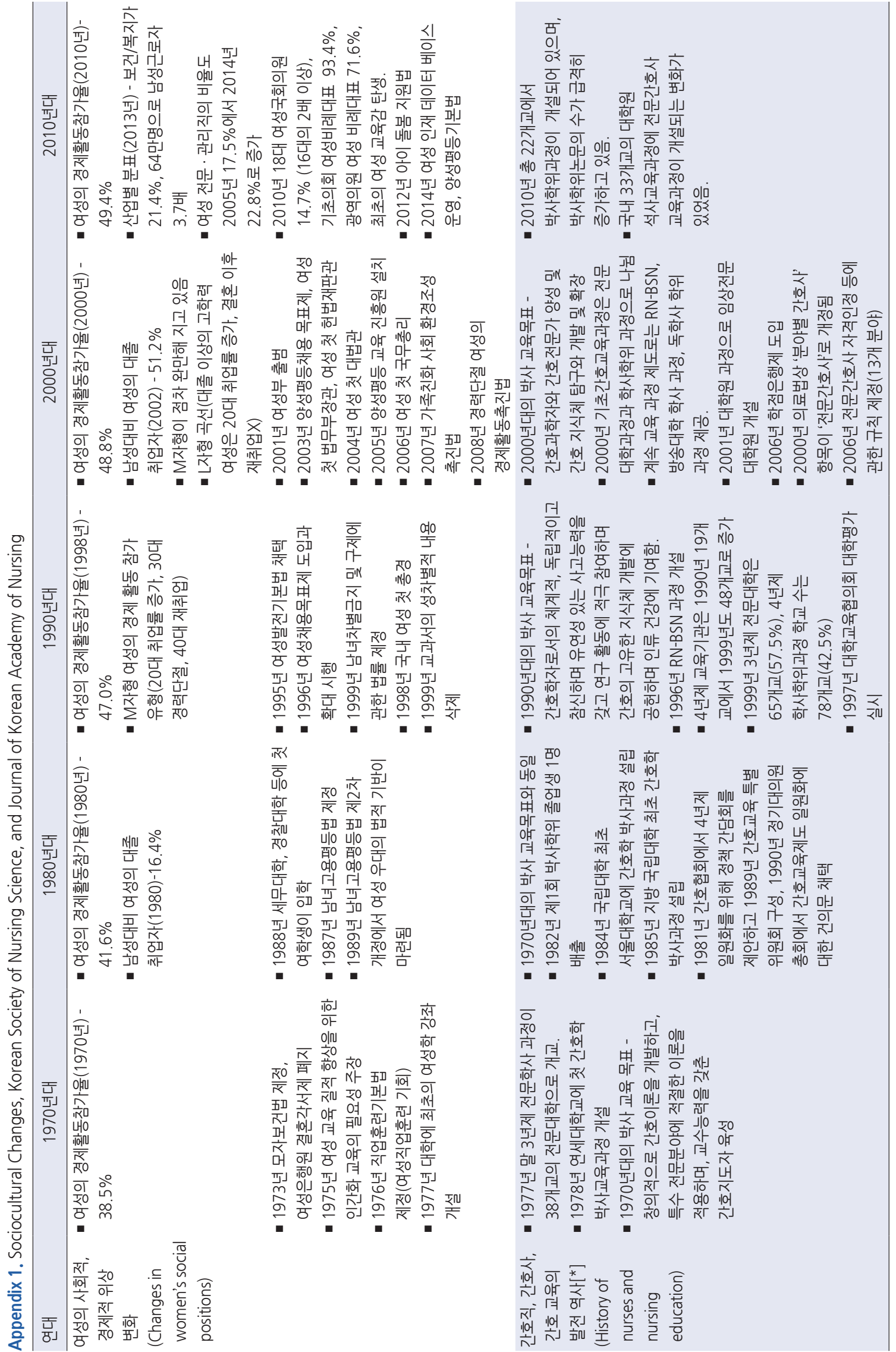




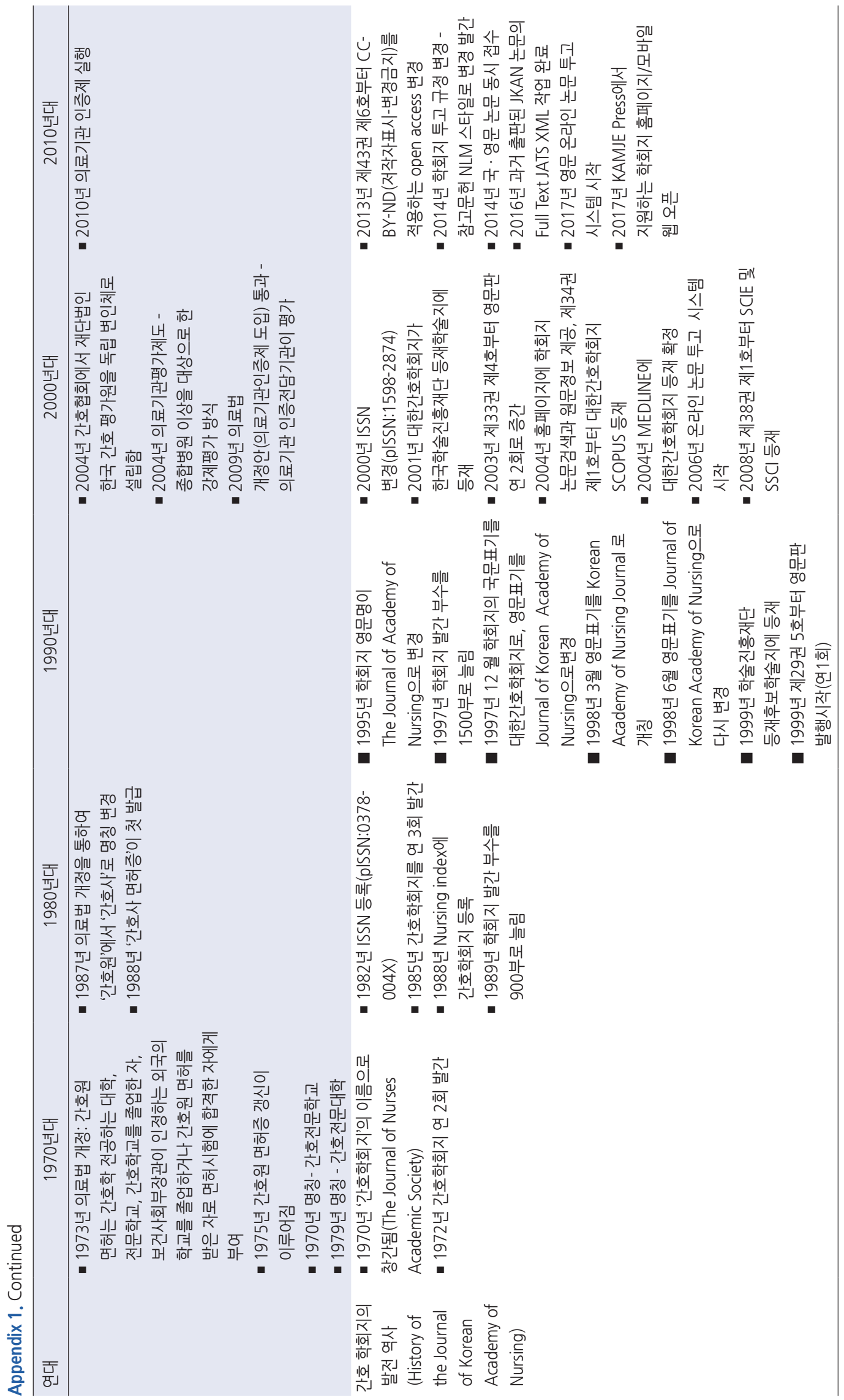




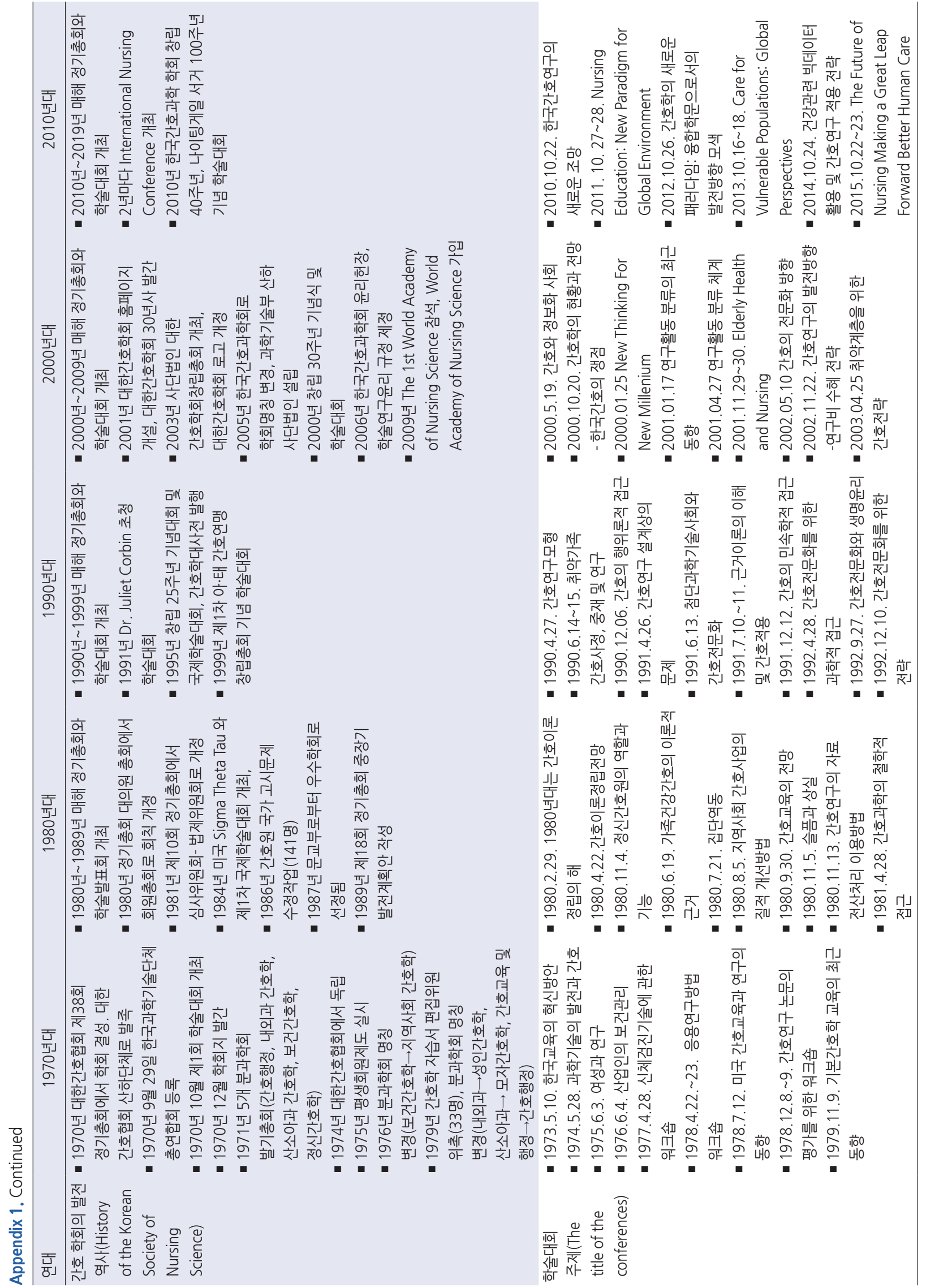




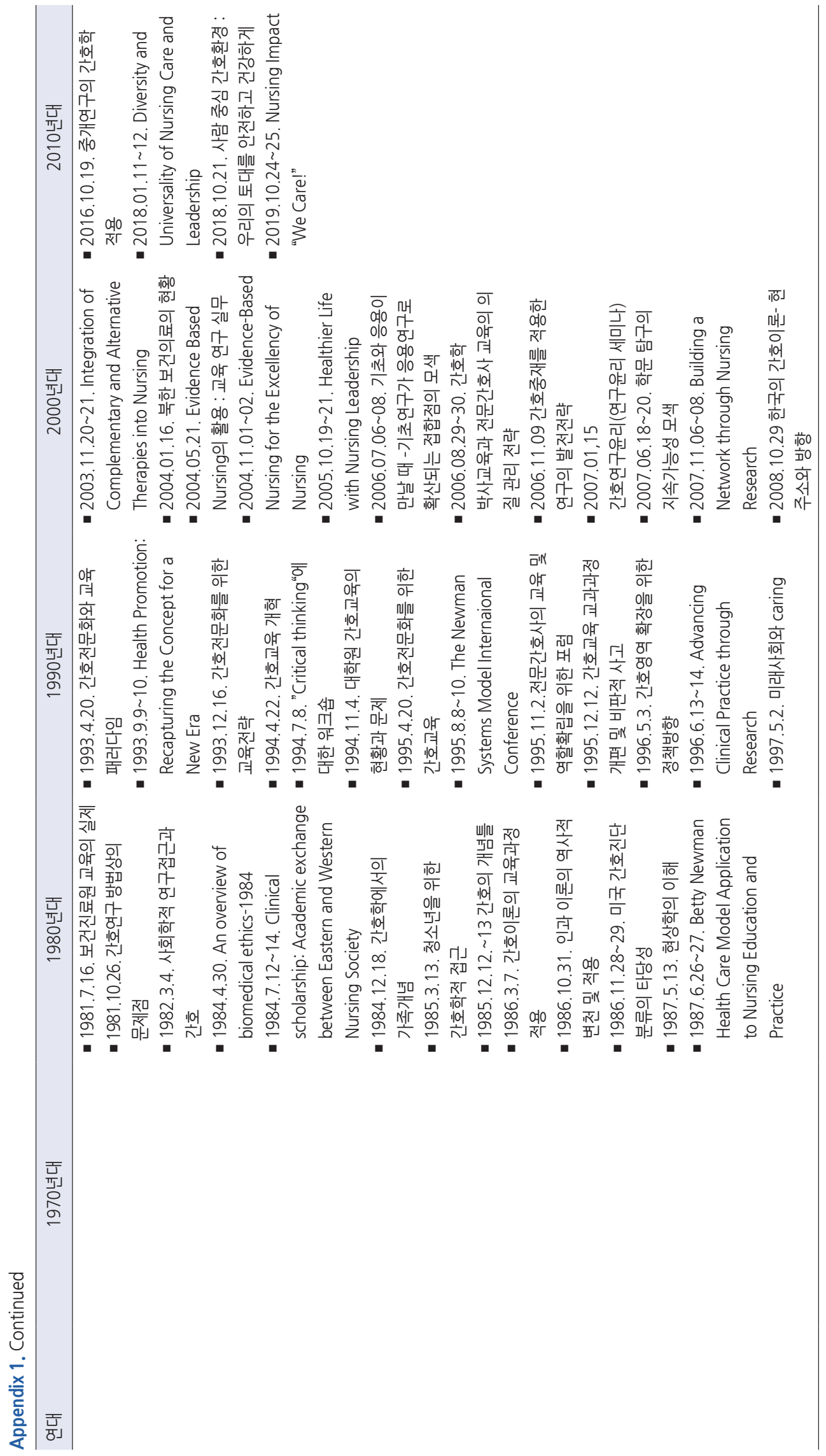




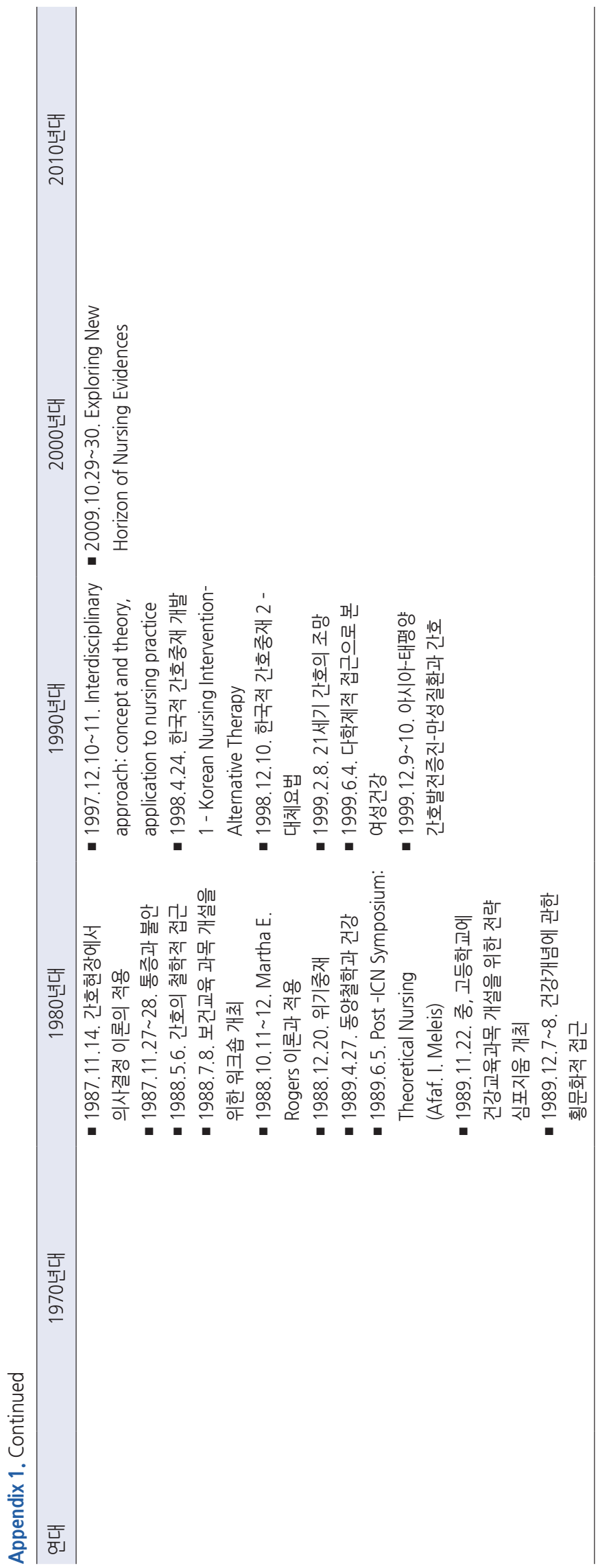


Appendix 2. The Results of Text Mining Analysis by VOSviewer

\begin{tabular}{|c|c|c|c|c|c|}
\hline \multicolumn{3}{|c|}{ 1970 1979 } & \multicolumn{3}{|c|}{$1980 \sim 1989$} \\
\hline Rank & Item (Occurrence) & Item (Relevance) & Rank & Item (Occurrence) & Item (Relevance) \\
\hline 1 & rate (44) & knowledge (3.8588) & 1 & scale (40) & experimental group (4.7722) \\
\hline 2 & student (41) & frequency (2.8013) & 2 & effect (35) & control group (4.5908) \\
\hline 3 & woman (41) & baby (2.2847) & 3 & problem (28) & state anxiety (3.6277) \\
\hline 4 & case (32) & doctor (2.0898) & 4 & hypothesis (26) & survey (1.9033) \\
\hline 5 & effect (27) & variable (2.0336) & 5 & instrument (25) & effect (1.805) \\
\hline 6 & response (27) & interest (1.9584) & 6 & activity (24) & self (1.7845) \\
\hline 7 & professor (27) & community (1.8555) & 7 & person (23) & case (1.7714) \\
\hline 8 & knowledge (26) & reason $(1.673)$ & 8 & anxiety (21) & hypothesis (1.3893) \\
\hline 9 & child (25) & mother (1.5983) & 9 & health (20) & health (1.3741) \\
\hline 10 & research (25) & correlation (1.4922) & 10 & process $(20)$ & sample (1.3058) \\
\hline 11 & correlation (24) & effect (1.4251) & 11 & development (20) & anxiety (1.1332) \\
\hline 12 & hypothesis (21) & student (1.416) & 12 & family (20) & researcher (1.0572) \\
\hline 13 & characteristic (21) & researcher (1.4023) & 13 & student (19) & process $(0.7947)$ \\
\hline 14 & development (21) & investigator (1.3812) & 14 & researcher (18) & perception $(0.7801)$ \\
\hline 15 & understanding (21) & control group (1.2997) & 15 & Korea (18) & knowledge (0.7695) \\
\hline 16 & mother (20) & comparison (1.2577) & 16 & use (18) & treatment $(0.7655)$ \\
\hline 17 & society (20) & parent (1.2391) & 17 & change (18) & woman (0.7323) \\
\hline 18 & influence (20) & hypothesis (1.239) & 18 & control group (17) & reliability (0.6781) \\
\hline 19 & medicine (19) & home (1.1806) & 19 & case (17) & home (0.643) \\
\hline 20 & doctor (18) & nursing education (1.1606) & 20 & sample (17) & Korea $(0.6377)$ \\
\hline 21 & reason (18) & characteristic (1.1124) & 21 & disease (17) & ANOVA (0.5956) \\
\hline 22 & improvement (18) & nursing student (0.9485) & 22 & attitude (17) & disease $(0.5889)$ \\
\hline 23 & tendency (18) & woman (0.9333) & 23 & experimental group (16) & nursing student (0.568) \\
\hline 24 & ability (18) & improvement (0.9165) & 24 & treatment (16) & attitude (0.5608) \\
\hline 25 & delivery (18) & content (0.909) & 25 & woman (16) & development (0.5599) \\
\hline 26 & duration (18) & responsibility $(0.9076)$ & 26 & relation (16) & change (0.5522) \\
\hline 27 & concept (18) & medicine (0.8645) & 27 & information (16) & research $(0.5352)$ \\
\hline 28 & nursing student (17) & case $(0.8448)$ & 28 & perception (15) & relation $(0.4939)$ \\
\hline 29 & t test (17) & $\mathrm{t}$ test $(0.841)$ & 29 & ANOVA (15) & scale $(0.4925)$ \\
\hline 30 & profession (17) & hospitalization (0.8041) & 30 & survey (14) & stress $(0.483)$ \\
\hline
\end{tabular}


Appendix 2. Continued

\begin{tabular}{|c|c|c|c|c|c|}
\hline \multicolumn{3}{|c|}{ 1990 1999 } & \multicolumn{3}{|c|}{$2000 \sim 2009$} \\
\hline Rank & Item (Occurrence) & Item (Relevance) & Rank & Item (Occurrence) & Item (Relevance) \\
\hline 1 & effect (178) & love (3.642) & 1 & effect (412) & structural model (3.711) \\
\hline 2 & score (148) & philosophy (3.3734) & 2 & control group (248) & preliminary item (3.4184) \\
\hline 3 & scale (137) & human being (3.3391) & 3 & experimental group (210) & Strauss (3.2564) \\
\hline 4 & significant difference (124) & Van Kaam (3.1427) & 4 & significant difference (184) & item analysis (3.079) \\
\hline 5 & test (117) & $\begin{array}{l}\text { diastolic blood pressure } \\
\text { (3.1096) }\end{array}$ & 5 & experience (161) & Cronbachs alpha (3.0345) \\
\hline 6 & experience (116) & theme (2.836) & 6 & $\mathrm{t}$ test (136) & path (3.0198) \\
\hline 7 & $\mathrm{t}$ test $(107)$ & health locus (2.7761) & 7 & process (125) & q statement (2.9908) \\
\hline 8 & variable (102) & stress management (2.7248) & 8 & descriptive statistic (120) & hypothetical model (2.9818) \\
\hline 9 & ANOVA (100) & principle (2.6523) & 9 & exercise (114) & empirical data (2.9578) \\
\hline 10 & process (95) & $\operatorname{mind}(2.5471)$ & 10 & instrument (113) & Corbin $(2.942)$ \\
\hline 11 & concept (88) & perspective (2.5132) & 11 & efficacy (111) & Lisrel (2.7896) \\
\hline 12 & instrument (86) & meaning (2.479) & 12 & variance (94) & conceptual framework (2.7521) \\
\hline 13 & system (85) & suffering (2.4104) & 13 & system (92) & content validity (2.7397) \\
\hline 14 & correlation (78) & depth interview (2.3715) & 14 & interview (91) & core category (2.7138) \\
\hline 15 & mother (70) & experiment (2.2439) & 15 & concept (89) & aromatherapy (2.6755) \\
\hline 16 & control group (69) & blood pressure (2.1423) & 16 & tool (79) & indirect effect (2.6202) \\
\hline 17 & knowledge (69) & consequence (2.1113) & 17 & theory (73) & fit (2.5991) \\
\hline 18 & meaning (63) & Pearson (2.106) & 18 & therapy (73) & diastolic blood pressure (2.5657) \\
\hline 19 & theory (61) & session (2.0726) & 19 & multiple regression (72) & theory method (2.52) \\
\hline 20 & category (59) & research question (2.0588) & 20 & social support (71) & total variance $(2.5031)$ \\
\hline 21 & experimental group (55) & description (2.0264) & 21 & approach (69) & direct effect (2.4611) \\
\hline 22 & rate $(55)$ & Scheffe test (1.9628) & 22 & correlation (69) & subjectivity (2.4562) \\
\hline 23 & role (54) & multiple regression (1.9429) & 23 & validity (68) & triglyceride (2.4538) \\
\hline 24 & content (52) & definition (1.8969) & 24 & role (67) & antecedent (2.4416) \\
\hline 25 & practice $(51)$ & body weight (1.8432) & 25 & general hospital (63) & Colaizzi (2.4261) \\
\hline 26 & methodology (49) & phenomenon (1.7878) & 26 & research design (63) & $\begin{array}{l}\text { significant influencing factor } \\
(2.4234)\end{array}$ \\
\hline 27 & exercise (48) & significant correlation (1.7794) & 27 & esteem (61) & q methodology (2.3047) \\
\hline 28 & reliability (48) & control group (1.7746) & 28 & function (61) & total cholesterol (2.2963) \\
\hline 29 & feeling (46) & harmony (1.7368) & 29 & reliability (61) & body composition (2.2736) \\
\hline 30 & validity (46) & Pearson correlation (1.723) & 30 & pearson correlation coefficient (58) & massage (2.2685) \\
\hline
\end{tabular}


Appendix 2. Continued

\begin{tabular}{|c|c|c|c|c|c|}
\hline \multicolumn{3}{|c|}{ 2010 2019 } & \multicolumn{3}{|c|}{$1970 \sim 2019$} \\
\hline Rank & Item (Occurrence) & Item (Relevance) & Rank & Item (Occurrence) & Item (Relevance) \\
\hline 1 & effect (299) & Corbins (2.6727) & 1 & effect (918) & $\begin{array}{l}\text { myofibrillar protein content } \\
(6.1634)\end{array}$ \\
\hline 2 & control group (207) & Strauss (2.4565) & 2 & control group (553) & plantaris (5.9925) \\
\hline 3 & experimental group (188) & total scale (2.374) & 3 & experimental group (482) & gastrocnemius (5.8504) \\
\hline 4 & scale (141) & core category (2.2625) & 4 & experience (412) & soleus (5.55) \\
\hline 5 & experience (109) & test retest reliability (2.2583) & 5 & model (371) & muscle atrophy (5.4269) \\
\hline 6 & significant difference (107) & factor loading (2.2504) & 6 & process (317) & muscle weight (5.4146) \\
\hline 7 & statistic (92) & $\begin{array}{l}\text { confirmatory factor analysis } \\
(2.1946)\end{array}$ & 7 & concept (235) & treadmill (4.2076) \\
\hline 8 & validity (87) & Cronbachs alpha (2.1733) & 8 & self efficacy (221) & normal distribution (3.8946) \\
\hline 9 & variance (76) & criterion (2.1646) & 9 & exercise (219) & q statement (3.6796) \\
\hline 10 & process (74) & criterion validity (2.1515) & 10 & descriptive statistic (218) & muscle (3.6193) \\
\hline 11 & reliability (74) & $\begin{array}{l}\text { internal consistency reliability } \\
(2.1005)\end{array}$ & 11 & variance (213) & quanl pc program (3.5408) \\
\hline 12 & session (71) & internal consistency (2.08) & 12 & validity (211) & exploratory (3.2046) \\
\hline 13 & difference (70) & direct effect (2.0755) & 13 & reliability (197) & $\begin{array}{l}\text { confirmatory factor analysis } \\
(3.1656)\end{array}$ \\
\hline 14 & $t$ test (69) & subscale $(2.0661)$ & 14 & SPSS (195) & $\begin{array}{l}\text { Cronbachs alpha coefficient } \\
\text { (3.0195) }\end{array}$ \\
\hline 15 & $\operatorname{AMOS}(68)$ & item analysis (2.0582) & 15 & social support (166) & construct validity (2.9706) \\
\hline 16 & rate $(68)$ & exogenous variable (2.0257) & 16 & collection (162) & Cronbachs alpha (2.9265) \\
\hline 17 & correlation (66) & $\begin{array}{l}\text { significant direct effect } \\
(1.9891)\end{array}$ & 17 & meaning (157) & $\begin{array}{l}\text { internal consistency reliability } \\
(2.8564)\end{array}$ \\
\hline 18 & instrument (63) & endogenous variable (1.9853) & 18 & understanding (145) & q methodology (2.8466) \\
\hline 19 & interview (62) & $\begin{array}{l}\text { nonequivalent control group } \\
\text { pretest posttest design } \\
(1.9673)\end{array}$ & 19 & $\begin{array}{l}\text { Pearson correlation coefficient } \\
\text { (132) }\end{array}$ & Corbins (2.7813) \\
\hline 20 & depth interview (58) & Corbins (2.6727) & 20 & depth interview (127) & exercise group (2.7549) \\
\hline 21 & tool (58) & Strauss (2.4565) & 21 & self esteem (126) & convergent validity (2.7029) \\
\hline 22 & social support (57) & total scale $(2.374)$ & 22 & factor analysis (121) & test retest reliability (2.6991) \\
\hline 23 & risk (54) & core category (2.2625) & 23 & literature review (119) & serum lipid (2.6429) \\
\hline 24 & effectiveness (52) & test retest reliability (2.2583) & 24 & research design (111) & total scale (2.623) \\
\hline 25 & exercise (44) & factor loading (2.2504) & 25 & multiple regression (107) & criterion validity (2.6052) \\
\hline 26 & literature review (44) & $\begin{array}{l}\text { confirmatory factor analysis } \\
(2.1946)\end{array}$ & 26 & nursing science (106) & food intake (2.5709) \\
\hline 27 & risk factor (42) & Cronbachs alpha (2.1733) & 27 & structure (105) & $\begin{array}{l}\text { exploratory factor analysis } \\
(2.5647)\end{array}$ \\
\hline 28 & Korean version (41) & criterion (2.1646) & 28 & adolescent (104) & psychometric testing (2.5636) \\
\hline 29 & hypothetical model (40) & criterion validity (2.1515) & 29 & feeling (101) & factor structure (2.5153) \\
\hline 30 & internal consistency (39) & $\begin{array}{l}\text { internal consistency reliability } \\
(2.1005)\end{array}$ & 30 & body (99) & concurrent validity (2.503) \\
\hline
\end{tabular}

